\title{
FÓRMULAS DE GUENTOS TRADICIONALES EN TEXTOS DEL SIGLO DE ORO
}

Varios eruditos - Leite de Vasconcelos, Francisco Rodríguez Marín, Joan Amades- ya han reunido fórmulas de cuentos tradicionales documentadas en textos del Siglo de Oro'. Propongo a continuación nueva lista de estas fórmulas que, a falta de ser exhaustiva, será más completa que las anteriores. Esta recopilación, además de confirmar el arraigo de los relatos tradicionales en la cultura áurea, sugiere una pregunta sobre la temática del cuento en fecha antigua y permite adelantar una hipótesis acerca del valor que otorgaban a las formas narrativas orales los escritores de los primeros decenios del siglo xvir.

\section{A. Fórmulas iniciales}

1. Fórmula simple: Érase que se era

1594

Lope de Vega, Laura perseguida, II, Acad. N., t. 7, p. 134b.

1596

Romance "En tiempo del rey Thereso [sic]/residía en Badajoz" (Las series valencianas del romancero nuevo y los cancionerillos de Munich,

1 Leite de Vasconcelos, "Fórmulas iniciaes e finaes dos contos", El folklore andaluz, Sevilla, 1882-1883 (y edición conmemorativa del Centenario, Madrid, 1981), pp. 211-215; Francisco Rodríguez Marín, "Varios juegos infantiles del siglo XVI", BRAE, 18 (1931), 667-670, y nota al Quijote, ed. 19471949 , t. 2, pp. 95-96; JoAn Amades, "Comentarios de novelística popular", $R D T P, 6(1950), 67-77$. 
1589-1602, ed. Antonio Rodríguez-Moñino, Valencia, 1963, núm. 110).

$$
\text { ¿1590-1605? }
$$

¿Lope de Vega?, El premio riguroso y amistad bien pagada, III, Acad. N., t. 1, p. 334b. ("Érase un Rey y una Reina").

\section{1}

Gabriel Lasso de la Vega, Manojuelo de romances, Saeta, Madrid: 1942, núms. 62, 66, 68.

Lope de Vega, El serafín humano, Dedicatoria, $B A E$, t. 178, p. C ("Erase un Rey y una Reina").

Alonso de Castillo Solórzano, Huerta de Valencia (texto citado por José María de Cossío, Fábulas mitológicas en España, Espasa-Calpe Madrid, 1952, p. 703).

\section{1}

García Medrano y Barrionuevo, Hero y Leandro, historia burlesca (Ga llardo, Ensayo, t. 3, p. 708).

Luis Quiñones de Benavente, La visita de la cárcel (Cotarelo y Mo ri, Colección de entremeses..., NBAE, ts. 17-18, p. 513a).

\section{7.}

Quevedo, "Érase que se era/(y es cuento gracioso)" (Poesía origi nal, ed. J. M. Blecua, núm. 774). 
1643

Quevedo, “Madre, asperísima sois/por de dentro, y por de fuera', (Poesía, núm. 705).

Quevedo, "Érase una cena/con cinco personas" (Poesía, núm. 799).

1663

Calderón, Las espigas de Ruth (Autos sacramentales, Aguilar, Madrid, 1967, p. 1095a).

\section{7}

Calderón, El postrer duelo de España, III, BAE, t. 14, p. 145b ("Érase una reina mora').

$1692-1694$

Francisco Bances Candano, Teatro de los teatros, Tamesis Books, London, 1970, p. 61.

2. Fórmula doble: Érase que se era, que norabuena sea

$$
\text { ¿1606-1609? }
$$

Lope de Vega, Del mal lo menos, II, Acad. N., t. 4, p. 464.

\section{4}

Alonso Fernández de Avellaneda, Don Quijote de la Mancha, Clásicos Castellanos, núm. 176, p. 14.

1620

Juan Cortés de Tolosa, Lazarillo de Manzanares, Clásicos Castellanos, núm. 186, p. 82. 
3. Fórmula compleja

Érase el que se era, el mal que se vaya, y el bien que se venga

(Versos del romance "Mujeres del tiempo/las que de discretas", Las series valencianas del romancero nuevo y los cancionerillos de Munich, 1589-1602, núm. 39).

1602

Érase que se era, y el bien para nosotros sea, el mal para la manceba del abad

(Alfonso Velázquez de Velasco, La Lena, Orígenes de la novela, III, $N B A E$, t. 8, p. 391b).

$1601-1603$

Érase que sea [sic], señores, una dama flaca y fea.

El bien para todos sea, mal para quien trate amores

(Lope de Vega, Los amantes sin amor, t. 3, Acad. N., III, p. 168b).

1605

Érase que se era; el bien que viniere para todos sea, y el mal para quien lo fuere a buscar (Quijote, I, 20).

1605

Érase que se era, que norabuena sea;

el bien que viniere para todos sea, y el mal váyase a volar

(Alonso de Ledesma, Juegos de Noches Buenas a lo divino, BAE, t. 35, núm. 401, p. 163a). 
1613-1615

Érase que se era

$[\ldots \ldots \ldots \ldots]$

que el bien para todos sea

(Lope de Vega, San Nicolás de Tolentino, III, BAE, t. 178, p. 114b).

\section{4}

Érase que se era, en hora buena sea, el mal que se vaya, el bien que se venga, a pesar de Menga

(Alonso Fernández de Avellaneda, Don Quijote de la Mancha, Clásicos Castellanos, núm. 175, p. 48).

Érase que se era, que en hora buena sea, el bien que viniere para todos sea, y el mal para la manceba del abad, frío y calentura para la amiga del cura, dolor de costado para la ama del vicario, y gota de coral para el rufo sacristán, hambre y pestilencia para los contrarios de la Iglesia (Alonso Fernández de Avellaneda, Don Quijote de la Mancha, Clásicos Castellanos, núm. 175, p. 167).

1622

Y el mal para quien le fuere a buscar y para la manceba del abad

(Quevedo, Sueño de la Muerte, Clásicos Castalia, núm. 50, p. 238).

Érase aquello que se era, el mal vaya y el bien venga

([?], El rey fingido y amores de Sancha, III, 'Acad. $N_{\text {i }}$, t. 1, p. 449a).

$\dot{¿} 1626$ ?

Érase lo que era, el mal que se vaya y el bien que se venga; el mal para los moros y el bien para nosotros

(Rodrigo Caro, Días geniales o lúdicros, Clásicos Castellanos, núm. 213, p. 200). 
Érase que se era, el bien para todos sea, y el mal para la manceba del abad.

Érase que se era, el mal que se vaya, y el bien que se venga (Correas, Vocabulario de refranes y frases proverbiales, Bordeaux, 1967, p. $82 a)$.

1631

Aténgome a las consejas de nuestros abuelos, con que sus viejas entretenían el hogar mejor que con las castañas, y al son del huso, comenzando con plegarias, no de vana intención en el suceso, del mal se vaya, el bien se venga, el mal para los moros, el bien para nosotros

(Rodrigo Fernández de Ribera, El mesón del mundo, Legasa, Madrid, 1979, p. 144).

1633

Érase que se era, que en hora buena sea, el bien que viniere para todos sea

(Quevedo, Perinola, Clásicos Castalia, núm. 113, p. 175).

Según advertirá el lector, se da una fuerte concentración de las fórmulas iniciales, cualquiera que sea su extensión, en los textos impresos hacia 1600-1630. Sería imprudente sacar de este hecho la conclusión de que los cuentos orales gozaran de boga excepcional entre los escritores de una generación determinada; más verosímilmente conviene atribuir el fenómeno a la coincidencia cronológica de dos series de causas: la época produce crecida cantidad de obras dramáticas y novelescas, los comediógrafos y los entremesistas apelan con frecuencia a las aludidas fórmulas.

\section{B. Fórmulas finales}

Aténgome a las consejas de nuestros abuelos, con que sus viejas entretenían el hogar mejor que con las castañas [...] y s $\epsilon$ contentaban con unos zapaticos de melcocha [...] y aun muchas veces se iban allá y nunca les daban nada 
(Rodrigo Fernández de Ribera, El mesón del mundo, p. 144).

Refleja la frase dos fórmulas finales de cuentos:

1. "A mí no me dieron nada", fórmula de las más frecuentes: véanse ejemplos en Aurelio M. Espinosa, Cuentos populares españoles, C.S.I.C., Madrid, 1946, núms. 99 (Zamora) y 110 (Cáceres), y en Julio Camarena Laucirica, Cuentos tradicionales recopilados en la provincia de Ciudad Real, Instituto de Estudios Manchegos, 1984, núms. 83 y 115.

2. "Me dieron unos zapaticos de melcocha [que se me derritieron en el camino]".

Estos zapatos frágiles también podían ser de papel en la tradición áurea, según documenta Correas:

Eran de papel, y mojóse, y acabóse.

Dicen esto al fin de un cuento. "Diéronme unos zapatitos de papel, y mojóse, y acabóse"

(Correas, Vocabulario de refranes, p. 615a).

En la tradición oral de fines del siglo xix y del siglo xx la prosaica manteca ha eliminado la superflua melcocha:

Y con esto yo víneme y dejélos allá; diéronme unos zapatinos

de mantega y derritiéronseme por el camino

(Cuentos asturianos recogidos de la tradición oral por Aurelio de Llano Roza de Ampudia, $2^{\mathrm{a}}$ ed., Delegación Provincial de Cultura, Oviedo, 1975, p. 32).

Ya no vi más porque me había hecho mi padre unas albarcas de manteca, y como hacía mucho calor, se me deshacían y me quedaba descalza y me tuve que venir

(Aurelio M. Espinosa, hijo, Cuentos populares de Castilla y León, C.S.I.C., Madrid, 1987-1988, t. 2, p. 23).

Me dieron unas alpargatillas de manteca, pa venime andando yo luego y, como hacía calor, pues se derritieron en el camino. Llegué aquí descarzo y to

(Julio Camarena Laucirica, Cuentos tradicionales. . . de Ciudad Real, p. 279).

Y yo fui y volví, y sólo me dieron unos zapatos de manteca que se me derritieron en el camino

(Sergio Hernández de Soto, Cuentos populares de Extremadura, Bi- 
blioteca de las Tradiciones Populares Españolas, Sevilla-Madrid, 18831886 , t. 10 , p. 116$)^{2}$.

$$
\text { C. La varita de virtudes }
$$

\section{Menciones}

Eugenio de Salazar, Carta IV, BAE, t. 176, p. $281 \mathrm{~b}$.

\section{4}

Lope de Vega, El leal criado, I, Acad. N., t. 7, p. $151 \mathrm{a}$.

$$
\text { ¿1608-1615? }
$$

Cervantes, Los baños de Argel, I, Comedias y entremeses, ed. SchevillBonilla, t. 1, p. 249.

Cervantes, Coloquio de los perros, Clásicos Castalia, núm. 122, p. 304.

$$
\text { ¿1626? }
$$

Rodrigo Caro, Días geniales o lúdicros, Clásicos Castellanos, núm. 213, p. 139 .

Correas, Vocabulario de refranes..., pp. 467a y $647 \mathrm{~b}$.

$$
1635
$$

Calderón, $A$ secreto agravio secreta venganza, II, $B A E$, t. 7, p. $601 \mathrm{~b}$.

${ }^{2}$ Sospecho que la frase de Evangelista " y en esto yo desperté, y halléme sin blanca ni cornado" ( $B A E$, t. 176, p. 14b) también refleja una fórmula final de cuento. 
Gracián, El Criticón, II, 3, Obras completas, Aguilar, Madrid, 1960, p. $702 a$.

2. Fórmula

Las viejas, cuando entretienen los niños contándoles algunas patrañas, suelen decir que cierta ninfa, con una vara en la mano, de oro, hace maravillas y tranmutaciones, aludiendo a la vara de Circe, encantadora, y usan de este término: "Varita, varita, por la virtud que Dios te dio, que hagas esto o estotro". (Covarrubias, Tesoro de la lengua castellana, p. 994a).

3. Fórmula parodiada

\section{4}

Varica, la mi varica, por la virtud que hay en ti, pues que jerigonza entiendes, que me traigas que muquir

(Versos del romance "En aquel siglo dorado/cuando floreció Amadís", incluido en el Romancero general y reproducido en Durán, núm. 1640).

1606-1615

¿1608-1611?

¡Puñalico, puñalico,

por la gracia que en ti reina,

que me mates sin matarme

donde mi ingrata lo vea!

(Lope de Vega, Los hidalgos del aldea, II, Acad. N., t. 6, p. 302b).

Varita, por la virtud que tienes, que me des luego un papelón de confites 
(Luis Quiñones de Benavente, Los alcaldes, Cotarelo y Mori, Colección de entremeses..., p. 662b).

La repetición insistente de estas alusiones sugiere que la varita de virtudes sería objeto mágico común en los relatos orales del siglo XVII, y el hada personaje clave de los mismos. En efecto hacia 1600-1650 mal pueden proceder el hada y su varita de fuentes escritas: ninguno de los textos medịevales españoles que mencionan las hadas ${ }^{3}$ se refiere a la asociación hada/varita, y todavía es lejana la fecha en que se han de imprimir los cuentos de Perrault. Contra toda verosimilitud Covarrubias, quien perfectamente conoce estos datos tradicionales, según demuestra el texto del Tesoro reproducido más arriba, pretende hacer del hada una figura esencialmente literaria:

Fadas o hadas llaman los escritores fabulosos de libros de caballerías a las ninfas o mujeres encantadas, que fingen no poder morir. $\mathrm{Y}$ dijéronse a fando, porque las introducen adivinando las cosas por venir. $\mathrm{Y}$ algunas veces puede haber sido que el demonio tome figura de tales personajes para engañar a los necios y codiciosos, porque dicen asistir en los lugares donde hay tesoros y los guardan ${ }^{4}$.

Aunque hadas y magas pertenecen a la misma familia de seres maravillosos, la identificación del hada de los cuentos y de la sabia Urganda es operación atrevida. Entre los textos que manejaban Covarrubias y sus contemporáneos ninguno les ofrecía la representación del binomio hada/varita, entonces privativo de la tradición oral. Sentado esto, no deja de sorprender a los curiosos del cuento tradicional la aceptación de que parece haber gozado el hada con varita entre los escritores en la primera mitad del siglo XVII. A pesar de que solemos hablar frecuentemente, con más pereza que exactitud, de "cuentos de hadas", el hada no es personaje tan común en el cuento europeo: más bien es personaje de leyendas. En la tradición española contemporánea aparece en dos tipos de relatos: La hermana buena y la hermana mala (T480) y La Cenicienta (T510A). Y tampoco reina en ellos con poder exclusivo: sufre la competencia victoriosa de la Virgen en el caso de La hermana buena. . ., la activa competencia de la madre de la he-

3 Véase la lista de estos textos en Julio Caro Baroja, Vidas mágicas $e$ Inquisición, Taurus, Madrid, 1967, t. 1, p. 164.

${ }^{4}$ Tesoro de la lengua castellana, p. 581a. La definición de la palabra hada (p. 674a) es, algo abreviada, fundamentalmente igual. 
roína y de la Virgen en el caso de La Cenicienta. (Por una contaminación elocuente, que no desmerece de los mejores hallazgos de la poesía paródica, aparece en alguna versión de La Cenicienta la Virgen provista de la varita de virtudes ${ }^{5}$.) ¿A qué conclusiones nos ha de llevar este contraste? Tan patente desnivel histórico, si en efecto conviene admitirlo, significaría que el hada jugaría papel mucho más importante en el folklore del siglo xviI que en el folklore contemporáneo. A no ser que tal desnivel sea ilusión pura, y que los escritores de 1600-1650 se hayan encaprichado, por motivos que se me escapan, con la varita de virtudes. No veo argumento decisivo que permita escoger entre ambas hipótesis.

\section{Ciensura de las fórmulas tradicionales}

Al muchacho que acaba de referirle un cuento le avisa el ermitaño de Lazarillo de Manzanares:

Gustado he de él [el cuento], Lázaro, porque lo has contado con gracia y agudeza $[\ldots]$ quiero $[\ldots]$ avisarte que no digas más "érase que se era", porque eso se ha de quedar para viejas y para ignorantes ${ }^{6}$.

Para viejas y para ignorantes... El texto interesa igualmente por su fecha (1620), tan cercana a la obra cervantina y a la obra lopesca, y por el hecho de que su autor, Juan Cortés de Tolosa, no suele brillar por la originalidad. Esta característica suya, que suele considerarse como inconveniente, ahora se convierte en ventaja: es razonable opinar que la frase refleja un concepto corrientemente admitido, el concepto según el cual los relatos tradicionales convienen a los ignorantes y a las viejas.

¿Por qué cuentos para ignorantes? Porque los ignorantes, los que no han estudiado, no alcanzan a conocer lo bello, son incapaces de percibir los valores estéticos. Los literatos perciben los valores estéticos, y por motivos estéticos desprecian el cuento tradicional. Sin duda chocó a aquellos hombres, que repitieron y glosaron con tanto ardor el famoso verso "che per tal variar natura è bella", la rigidez estructural del cuento, su carácter repetitivo, su inmovilidad que debió de parecerles cadavérica. Adelanto esta

${ }^{5}$ Aurelio M. Espinosa, Cuentos populares españoles, C.S.I.C., Madrid, 1946, núm. 112.

${ }^{6}$ Juan Cortés de Tolosa, Lazarillo de Manzanares, Clásicos Castellanos, núm. 186, p. 84. 
hipótesis porque la apreciación de Juan Cortés de Tolosa no es ejemplo aislado. Confirman la censura que expresa Lazarillo de Manzanares unos versos de Luis Quiñones de Benavente:

\title{
LA MALCONTENTA
}

Quiteria, ¿sabes cuentos?

\section{QUITERIA}

\author{
Sí, señora
}

\section{LA MALCONTENTA}

Pues dime uno sin "érase que se era", "dejémelos allá", ni rey con hijos que piden bendición, caballo y armas, y si ha de ser con esos adherentes, antes te lleve el diablo que lo cuentes ${ }^{7}$.

De la misma manera debió de opinar la generalidad de los hom bres cultos hacia 1600. Así lo siente Alonso Quijano, según de muestra la glosa irónica que aplica al cuento tradicional referidc por Sancho (porque la voz que se oye en este fragmento es la voz del hidalgo culto, no la del andante alucinado por sus descomul. gadas novelas): "Dígote de verdad que tú has contado una de la: más nuevas consejas, cuento o historia, que nadie pudo pensai en el mundo, y que tal modo de contarla ni dejarla jamás se po drá ver ni habrá visto en toda la vida..." Este desdén por la: formas de la narración oral explica la conducta de los escritore: del Siglo de Oro: buenos conocedores de los cuentos tradiciona les, los aprovechan parca y prudentemente, reservándolos a uno: empleos bien definidos y poniéndolos en boca de personajes cui dadosamente escogidos.

Maxime Chevaliei

Université de Bordeau:

7 Luis Quiñones de Benavente, La malcontenta, en Cotarelo y Mori, Co lección de entremeses. . , NBAE, ts. 17-18, p. 740a. "Dejémelos allá" debe refle jar otra fórmula final de cuento. 